\title{
DERRIDA SOBRE FREUD. ESCRITURAS SOBRE EL IMPOSIBLE SUJETO
}

\author{
Nicolás Fuster Sánchez* \\ Pedro Moscoso-Flores**
}

\begin{abstract}
El presente texto aborda el problema del psicoanálisis, y la relación crítica que Jacques Derrida articula entre éste y la filosofía metafísica, profundizando en aquellos aspectos de la teoría freudiana que sirven como referente subversivo al pensamiento ilustrado en torno a la subjetividad. Se tomará como referencia fundamental el problema del inconsciente y de la muerte como elemento clave para cuestionar el problema del sujeto desde una visión ontológica y/o idealista.
\end{abstract}

Palabras clave: psicoanálisis, pulsión de muerte, identidad, différance, repetición.

\section{DERRIDA ON FREUD. WRITINGS ON THE SUBJECT IMPOSSIBLE}

This paper addresses the problem of psychoanalysis and the critical relationship that Jacques Derrida articulates between the later and metaphysical philosophy, delving into those aspects of Freudian theory that serve as a subversive reference to the enlightened thought concerning subjectivity. It will be taken as fundamental reference the issue of unconsciousness and death as a key element to challenge the problem of the subject from an ontological and/or idealistic perspective.

Keywords: psychoanalysis, death drive, identity, différance, repetition.

\footnotetext{
*Universidad de Valparaíso, Valparaíso, Chile. Correo electrónico: nfusters@gmail.com

**Universidad Central, Santiago, Chile. Correo electrónico: pmoscosoflores@gmail.com
} 

"Hay que pensar la vida como huella antes de determinar el ser como presencia. Esa es la única condición para poder decir que la vida es la muerte, que la repetición y el más allá del principio del placer son originarios y congénitos de aquello que precisamente transgreden".

DERRIDA, J.

El PRESENTE TEXTO INTENTA PONER en RELIEVE LA PARTICULAR relación entre Derrida y el psicoanálisis, a propósito del problema del sujeto como categoría crítica que se juega propiamente dentro de los discursos filosóficos modernos. En el caso de Derrida, y usando sus propias palabras, sería más preciso hablar de una suerte de impresión freudiana, en la que muchas veces cuesta diferenciar qué espectro es el que habla: el filósofo aparece como un psicoanalista, analizando al psicoanálisis desde el psicoanálisis. Por su parte Freud, interpelado por el mismo Derrida, aparece como espectro, deconstruyendo los discursos de la metafísica de la presencia logofonocéntrica. De esta forma se pone en juego, en la misma relación tensionada que no acaba de clausurarse, aquello que su texto manifiesta: hay una alianza ominosa entre ambos, una relación que se inscribe en el límite, en la marginalidad del texto. Es ahí donde los conceptos freudianos, legados de la metafísica de la presencia, se subvierten para dar paso a la monstruosidad: "Freud recurre a una grafía que no está nunca sometida, como exterior y posterior, a la palabra [...] mediante la insistencia de su inversión metafórica, vuelve enigmático, por el contrario, aquello que se cree conocer bajo el nombre de escritura"'.

Por lo tanto, cabría preguntarse qué es lo que une a estos dos pensadores y, a su vez en la misma pregunta, insertar la cuestión respecto a las condiciones de posibilidad de pensar dicha unión. En este sentido se nos viene a la mente el simulacro, es decir, aquello que exige la aparición de la conceptualidad freudiana como único modo posible de su propia deconstrucción. Del mismo modo que el inconsciente psicoanalítico presupone una relación que siempre se mantiene entre la familiaridad y la extrañeza, la relación entre ambos espacios discursivos (psicoanálisis y deconstrucción) sería solamente posible de pensar desde este lugar, es decir, el de sus propias resistencias.

Desde la deconstrucción temprana del logocentrismo, y el análisis temprano de la represión de la escritura como una forma de constituir el saber occidental, Derrida encuentra un fuerte aliado en Freud. El pensador francés encontrará en el psicoanálisis un espacio de superación de las dualidades en torno a oposiciones que sostienen la metafísica de la presencia.

1 Derrida, Jacques, La Escritura y la Diferencia, Anthropos, Barcelona, 1989, p. 275. 
Lo anterior, precisamente, a propósito de la conciencia del inconsciente, en lo que puede leerse como una doble operación: por un lado, en la emergencia del inconsciente como figura epistemológica que viene a alterar el devenir continuo e inalterado presente en la filosofía del sujeto moderno, poniendo a este último en nuevo escenario de angustia frente al extrañamiento de lo propio. Por otro, a nivel teorético, a partir del posicionamiento del inconsciente como una suerte de parásito constitutivo de la conciencia: "Es que sin duda también en el interior del yo es mucho lo inconciente: justamente lo que puede llamarse el núcleo del yo; abarcamos sólo una pequeña parte de eso con el nombre de preconciente"2. En esta misma línea, y reforzando lo anterior, ya no será posible pensar en un placer como opuesto al displacer: "Así nos convencemos que aún bajo el imperio del principio del placer existen suficientes medios y vías para convertir en objeto de recuerdo y elaboración anímica lo que en sí mismo es displacentero"3.

Lo llamativo de esto radica en que, en la medida que Freud propone la primacía del inconsciente al manifestar que no se constituye exclusivamente como una representación traumática desplazada e intolerable para la conciencia, pone a esta última en una posición des-apropiada, es decir, como un efecto del ejercicio de desplazamiento inconsciente. Esto permitirá, en definitiva, abandonar la tesis de la presencia originaria reprimida como constituyente del sujeto. Más aún, cuando Freud introduce su pulsión de muerte como elemento constitutivo del sujeto en su obra Más allá del principio del placer, rompe con la oposición binaria entre vida y muerte a partir de una distinción -diferida- entre placer y displacer. En suma, se instala la presencia de la muerte acechando a la vida desde su origen:

Una pulsión sería entonces un esfuerzo, inherente a lo orgánico vivo, de reproducción de un estado anterior que lo vivo debió resignar bajo el influjo de fuerzas perturbadoras externas; sería una suerte de elasticidad orgánica o, si se quiere, la exteriorización de la inercia en la vida orgánica [...] Si nos es lícito admitir como experiencia sin excepciones que todo lo vivo muere, regresa a lo inorgánico, por razones internas, no podemos decir otra cosa que esto: la meta de toda vida es la muerte; $y$, retrospectivamente: lo inanimado estuvo ahí antes que lo vivo ${ }^{4}$.

Así, la analítica de la muerte dentro del (con)texto freudiano vendría a provocar un nuevo giro crítico en la metafísica de la presencia, ya que dejaría de actuar en oposición a la vida pasando a ser parte estructurante de la misma. En otras palabras, la muerte perdería su condición des-apropiadora de la vida -en tanto oposición-, aspecto que se materializaría a partir de la inclusión de su tesis respecto a la compulsión a la repetición. En tal

2 Freud, Sigmund, "Más allá del Principio del Placer", en Obras Completas, vol. XVIII, Amorrortu, Buenos Aires, 2001, p. 19.

3 Ibidem, p. 17.

4 Ibidem, pp. 36-38. 
sentido, el psicoanalista Freud no abandona su tesis esencialista sobre el sujeto, pero sí la subvierte al establecer lo inorgánico como lo originario.

Antes de proseguir, creemos necesario situar lo anterior dentro del contexto de la conformación del sujeto psicoanalítico freudiano. Para esto retomamos algunas claves del texto freudiano Introducción al Narcisismo (1914), específicamente en lo que concierne a la constitución del aparato psíquico. Recordemos que Freud apela a la existencia de un estado originario, de indiferenciación, en que el sujeto aún no se ha constituido como tal: "Es un supuesto necesario que no esté presente desde el comienzo en el individuo una unidad comparable al yo; el yo tiene que ser desarrollado. Ahora bien, las pulsiones autoeróticas son iniciales, primordiales; por tanto, algo tiene que agregarse al autoerotismo, una nueva acción psíquica, para que el narcisismo se constituya"5.

Dichas pulsiones, parciales y autoeróticas, formarían parte de un principio de autoconservación y solamente vendrían a instaurarse como figuras de completitud a partir de la reconducción de la libido hacia otro, operando éste último como una suerte de espejo que hace posible y es posible en base a la capacidad de representación. Sin embargo, dirá Freud, en un intento por recuperar el autoerotismo perdido habría una segunda reconducción de la libido hacia sí mismo que devendría en esta figura conformada del yo, como expresión clausurada de la conciencia de sí: "Así, nos vemos llevados a concebir el narcisismo que nace por replegamiento de las investiduras de objeto como un narcisismo secundario que se edifica sobre la base de otro, primario, oscurecido por múltiples influencias"6.

Por lo tanto, podemos ver cómo se establece un quiebre en relación con las concepciones sustancialistas -cartesianas-e idealistas -hegelianas-kantianas- del sujeto, propias de las tradiciones filosóficas modernas: la explicación neuro-psíquica de la producción del yo parece sostenerse en base a un aparente reconocimiento pseudo dialéctico de una figura especularizada ( $p$ seudo, dado que se constituye en el registro de la representación), re-conocimiento del otro que (soy) yo como condición sine qua non para su aparición y subsistencia. Sin embargo, concluimos que a partir de esto el sujeto-sustancia no podría ser pensado como resultado de la síntesis simple y perfecta, sino como el producto de una tensión inevitable y una pérdida originaria que se ejerce en cada momento a la manera de una moción pulsional sin destino.

La paradoja de la composición del yo, como figura de función representacional y captadora de la sensibilidad fenoménica, es el gesto de constante reminiscencia a un origen -desconocido- como intento infructuoso por recuperar algo de lo que nunca ha sabido. En esta línea, podríamos señalar que la re-presentación se sitúa como figura análoga a la

5 Freud, Sigmund, "Introducción al Narcisismo", en Obras Completas, vol. XIV, Amorrortu, Buenos Aires, 2001, p. 74 .

6 Ibídem., p. 72. 
re-petición (re-volver atrás; petere-buscar, intentar, apetecer), como una re-vuelta (en su doble acepción: como retorno, pero también como sublevación, insurrección) sobre algo a lo que nunca se puede acceder en tanto objeto constitucionalmente perdido, obligando a la conciencia a buscar objetos subsidiarios que lo reemplacen. Por lo tanto, existiría una barrera infranqueable y fundamental en el espacio que queda entre aquel objeto perdido y la representación en que la vida (pulsión de autoconservación) se jugaría en un desplazamiento de recuperación. Desplazamiento por siempre fallido en cuanto a su objetivo, ya que se puede realizar únicamente a partir de la investidura de objeto, por lo que el sujeto se anclaría en un proceso de exteriorización constante de sí mismo, en una situación de precariedad y fragilidad inmanente. Así, cobra sentido la lectura que hace el propio Derrida a propósito de la conciencia freudiana, como el efecto de un origen diferido y especularizado, o en otros términos, sin presencia originaria: una conciencia originariamente diferida.

A pesar de lo anterior, el propio Freud parece realizar una suerte de gesto crítico sobre su proyecto, al obrar un desplazamiento en la formación del aparato psíquico desde una concepción psicológica a una concepción metapsicológica. En El Yo y el Ello (1923), plantea un punto de inflexión respecto a la premisa fundamental del psicoanálisis, a saber, "la diferenciación de lo psíquico en consciente e inconsciente [...]"7 . A lo anterior agrega lo que puede ser interpretado como un (des)anudamiento del problema concerniente a la filosofía de la conciencia, a propósito de su propia negación permanente a los saberes filosóficos, en relación al sujeto:

El psicoanálisis no puede situar en la conciencia la esencia de lo psíquico, sino que se ve obligado a considerar la conciencia como una cualidad de lo psíquico que puede añadirse a otras cualidades o faltar [...] Para la mayoría de las personas de formación filosófica, la idea de algo psíquico que no sea también conciente es tan inconcebible que les parece absurda y desechable por mera aplicación de la lógica [...] Y bien; su psicología de la conciencia es incapaz, por cierto, de solucionar los problemas del sueño y de la hipnosis ${ }^{8}$.

Dicho gesto freudiano puede ser interpretado como un intento de distanciar a la conciencia de la razón, al otorgarle a la primera el carácter de estado transitorio y fugaz. Lo anterior se ve claramente reflejado en el juego semántico que postula Freud, al situar la conciencia en una relación de potencialidad -o susceptibilidad de conciencia-, es decir, como algo que ha sido consciente pero que ya no lo es, lo que podría significar que la ausencia de la moción pulsional representada pasaría a cobrar un carácter inconsciente: "Eso inconciente coincide, entonces, con latente-susceptible de conciencia". Sin embargo, simultáneamente admite que hasta ese momento había llegado a pensar lo inconsciente de manera muy distinta:

7 Freud, Sigmund, "El Yo y el Ello", en Obras Completas, vol. XIX, Amorrortu, Buenos Aires, 2001, p. 15. 8 Ídem. 
[...] existen procesos anímicos o representaciones muy intensos -aquí entra en cuenta por primera vez un factor cuantitativo y, por tanto, económico-que, como cualesquiera otras representaciones, pueden tener plenas consecuencias para la vida anímica (incluso consecuencias que a su vez pueden devenir concientes en calidad de representaciones), sólo que ellos mismos no devienen concientes ${ }^{10}$.

Esta visión dinámica del inconsciente - por cierto, la más tradicional dentro del freudismo- a partir de la doctrina de la represión, es decir, como incapaz de conciencia, constituiría el segundo sentido del inconsciente. A dicha problemática se le sumaría un tercer sentido, fundamentado en un yo que fiscaliza todos los procesos que gobiernan la motilidad y desde donde partirían las represiones y las resistencias: "[...] lo decimos entonces que se halla bajo el dominio de la resistencia, pero él no sabe nada de ella"11. Este último sentido sería justamente aquel aspecto inconsciente de la conciencia al que nos referimos anteriormente. Por lo tanto, lo inconsciente adquiere un carácter polimorfo y difuso, perdiendo su función de límite demarcatorio dentro del proyecto freudiano.

Esta inversión de los conceptos freudianos, a juicio de Derrida, permite reconducir la mirada desde una teoría neurológica de la memoria hacia una teoría de la huella, del archivo y de la escritura: "Mediante la insistencia de su inversión metafórica, vuelve enigmático, por el contrario, aquello que se cree conocer bajo el nombre de escritura [...] el contenido de lo psíquico será representado por un texto en esencia irreductiblemente gráfica. La estructura del aparato psíquico será representada por una máquina de escribir"'12.

Así, al plantear la esencia misma de lo psíquico como el movimiento de abrirse paso de las neuronas para dar cuenta de la memoria, Freud estaría intuyendo la formación psíquica a partir de una resistencia de fuerzas y de diferencias como determinantes en dicho proceso. Frente a lo anterior, Derrida establecerá que todas las diferencias en la producción de la huella pueden reinterpretarse como momentos de la différance:

El gasto o la presencia amenazadores son diferidos con la ayuda del abrirse-paso o de la repetición. ¿No es ya esto el rodeo que instaura la relación del placer con la realidad? ¿No es esto la muerte en el principio de una vida que no puede defenderse contra la muerte más que por la economía de la muerte, la diferancia, la repetición, la reserva? Pues la repetición no sobreviene a la impresión primera, su posibilidad está ya ahí, en la resistencia que ofrecen las neuronas psíquicas la primera vez [...] Por lo tanto, la vida está amenazada desde el comienzo por la memoria que la constituye y por el abrirse-paso al que resiste, rotura que no puede contener más que repitiéndola ${ }^{13}$.

9 Ibidem., p. 16.

10 Ibídem., p. 549

11 Ibídem., p. 552.

12 Derrida, Jacques, "Freud y la Escena de la Escritura", en La Escritura y la Diferencia, op. cit., p. 275. 
Según esto, se hace viable pensar que la vida se protege a sí misma (de sí misma) mediante la repetición, la huella, la diferancia; pero no en la lógica que exista una vida primero que haya que venir a proteger. La diferancia constituiría la esencia misma de la vida. Esto nos lleva a borrar el mito del origen presente con el que el mismo Freud parece titubear: hay una demora constitutiva que remite a un no-origen originario. Por lo tanto, nos vemos obligados a dejar de lado la idea de la différance simplemente como movimiento. La vida sería, en sí misma, este diferir basado en una reproducción de sentido constituido por retardo, a destiempo.

Como ya notamos, este retardo o différance a la que se refiere Derrida da cuenta de una cierta economía ligada a la escritura. Escritura entendida en un sentido otro, como aquella que determina tanto al habla como a lo escrito. Esta palabra, que en sus raíces idiomáticas conserva un cierto juego con la palabra diferencia (juego que consiste en la imposibilidad de diferenciarlos, más si no es a partir del hablar acerca de...), diríamos que es la que permite que existan estructuras de diferencias, a la manera de una cierta estructura del Orden discursivo que permitiría la existencia de determinados órdenes, lo que nos retrotrae a la figura del unario primitivo lacaniano. La différance, al no oírse y permanecer silenciosa, operaría como la tumba en esta estructura sepulcral (oikevis). Una tumba que no se puede ni siquiera hacer resonar, pero que permite que se estructure un lenguaje fonético como únicamente fonético ${ }^{14}$. Por lo tanto, habría que pensar esta noción desde un nuevo orden que se resista a la oposición entre lo sensible e inteligible; elemento constitutivo que cuestiona el principio de derecho - arkhé-, como aquel que intenta proponer un sentido último, que permite pensar la diferencia entre palabra y escritura.

De este modo se pueden apreciar algunas similitudes en relación con la constitución psíquica freudiana y la différance derridiana, entendiendo esto último como movimiento estructurante de temporización y espaciamiento. Movimiento que no cesa de avanzar, más sin ganar terreno. El yo consciente se constituye como un amo, más está siempre sujeto a otro que (es) él mismo. Se podría pensar así una nueva lectura del descentramiento freudiano del yo de la conciencia, quedando éste relegado a una función suplementaria cuyo único logro habría sido el de generar una concesión económica hacia el principio del placer. La posibilidad de repetir lo que en un registro puede ser displacentero (a saber, el síntoma para el yo), constituiría la ganancia del registro inconsciente del ello y, si se quiere, posibilidad de la metafísica de la presencia. A pesar de esta aparente atomización del aparato psíquico, no existiría una diferencia estructural entre las instancias psíquicas, sino que la conciencia estaría constituida en una especie de différance o estructuralidad de la estructura, por exposición a una (imagen de) realidad.

Se puede ver cómo es que en el Más allá del principio del placer de Freud aparece la soberanía del principio del placer como gobernante de la psiquis inconsciente. Como ya

14 Derrida, Jacques, "La Différance”, en Márgenes de la Filosofía, Cátedra, Madrid, 1988. 
planteamos, esto representa un primer gran quiebre para la tradición moderna en la medida que se tiende a relegar el principio de realidad a una función secundaria, quedando el sujeto kantiano, el del giro copernicano, completamente desgarrado. La represión, como mecanismo central de la psique, es lo que complica la lógica implícita de toda filosofía, a saber, hacer que un placer pueda ser experimentado como displacer. Esto desestabiliza a toda la tradición filosófica y científica, puesto que la experiencia sensible ya no podría ser tomada como el criterio de distinción entre placer y displacer.

Además, la soberanía del principio del placer significa que la psiquis inconsciente está en el origen de todo lo que podría sucederle. Ella se apropia en el origen de lo que le es extraño y que viene del otro. Lo que está en juego con lo anterior es el pensamiento freudiano de lo propio, de la identidad. Pero el origen, en tanto acontecimiento, estaría marcado no sólo por la apropiación de lo propio, sino también por una cierta expropiación que se abre y resiste a la experiencia: una cierta inapropiabilidad. En este sentido, Derrida dirá que el principio de realidad es la única manifestación posible del principio del placer, siendo el primero un instrumento del segundo y no un principio independiente. En otras palabras, el principio de realidad sería el resultado de un movimiento provocado por una suerte de negociación del principio del placer con la realidad, en que el placer debe morir (un poco) para vivir (un poco) ${ }^{15}$.

Volviendo a Freud, podríamos señalar que su "tesis irresistible" fue esta pulsión de agresión original y autónoma, derivando simultáneamente en una modificación de la doctrina psicoanalítica de las pulsiones. Sin embargo, a pesar que logra reconocer la concepción dualista de su doctrina pulsional, insiste en hacer el ejercicio explicativo respecto a una fractura interna de la pulsión, situando la dualidad en la profundidad de la psiquis. Así, comenta la aparición de la pulsión de pérdida a partir de la pulsión sexual o de autoconservación: "El propio amor de objeto nos enseña una segunda polaridad de esta clase, la que media entre amor (ternura) y odio (agresión). ¡Si consiguiéramos poner en relación recíproca estas dos polaridades, reconducir la una a la otra! Desde siempre hemos reconocido un componente sádico en la pulsión sexual [...]"16.

Por ende, la pulsión de muerte sería la modalidad pulsional por la que el yo se afirma y se conserva. De allí que la pulsión de muerte sea entendida como el movimiento de dominio y de constitución indefinida de lo propio. Esto significa que el dominio se deconstruye en el movimiento mismo en que se asegura. De tal modo que la pulsión de muerte no podría ser considerada como un principio, sino como todo lo contrario: es la amenaza de toda principalidad, toda primacía arcóntica, todo deseo de archivo. Es, según Derrida, en el mal de archivo donde la psiquis se conserva destruyéndose: "No hay archivo sin lugar de consignación, sin una técnica de repetición y sin una cierta exterioridad. Ningún

15 Cfr. Goldschmidt, Marc, Jacques Derrida. Una introducción, Nueva Visión, Buenos Aires, 2004.

16 Freud, Sigmund, Màs alla..., op. cit., p. 52. 
archivo sin afuera"17. Por ende, si no se puede pensar el archivo más que desde un afuera, un lugar en que se pueda repetir, habría que advertir la relación entre la repetición y la compulsión a la repetición de la pulsión de muerte. Esto hace que aquello que permite la constitución del archivo es, en sí mismo, la condición de su destrucción: "El archivo trabaja siempre y a priori contra sí mismo"18.

En resumen, hemos llegado a establecer cómo, para Derrida y para Freud, la vida no existe más que en relación con la muerte, es decir, una economía de la muerte original y constituyente. En Más allá del principio del placer, Freud plantea que los procesos primarios no buscan más que alivio, placer, cueste lo que cueste, sin tener este impulso una conexión necesaria con la supervivencia del sistema. Serían, en efecto, los procesos secundarios los que unirían ambas necesidades. Por lo tanto, subsistiría una tensión dialéctica entre el alivio a partir de la desunión absoluta -en tanto muerte inmanente- y la unión total como opresión asfixiante. Es por esto que el aparato psíquico debe protegerse, en un doble gesto, contra su propio exceso de vida y su exceso de protección. El principio del placer es quien designa aquí a ese conjunto, en que el principio de realidad le rinde tributo al oponerle obstáculos que le obligan a perseguir su fin pasando por el diferimiento. Sería la estructura del mismo no-idéntico. Lo que Derrida denomina la vida, la muerte ${ }^{19}$.

Según la hipótesis del psicoanalista, la vida es el desvío de lo inorgánico hacia sí mismo: el principio del placer difiere la concentración o la retirada mortal en beneficio de un movimiento garantizado por los impulsos parciales, hacia una muerte que sería propia del ser vivo, de modo que lo propio del ser vivo sería reapropiarse limpiamente de aquello que lo desapropia: el abismo de lo propio. La esencia del ser vivo se constituye como este desvío hacia lo suyo propio, su propia muerte ${ }^{20}$.

En este punto nos detendremos en algunas consideraciones realizadas por Derrida, a propósito de su propia lectura del Más allá...freudiano. En primer término, hace explícito el fracaso del psicoanálisis como saber puramente interpretativo. El concepto de transferencia viene a dar cuenta de lo anterior, en tanto momento de un análisis que no hace más que desplazar la resistencia. Así, por ejemplo, al describir Freud las llamadas neurosis de transferencia, sitúa el acto de reproducción en el mismo lugar que la repetición, es decir, como acto que depende de su performatividad, como acto de desplazamiento de un objeto de un lugar a otro, eliminando la idea del retorno de lo reprimido. Dicha repetición, en tanto reproducción en sí misma, sería la reproducción del momento originario, de la-vidala-muerte como una cadena significante imposible de desbrozar. Lo anterior queda patente a propósito de las neurosis traumáticas, cuando Freud nos dice que: "el hecho de que el mismo cuadro patológico sobrevenía en ocasiones sin la cooperación de una violencia

17 Derrida, Jacques, Mal de Archivo. Una impresión freudiana, Trotta, Madrid, 1997, p. 19.

18 Idem., p. 20.

19 Cfr. Bennington, Geoffrey, Jacques Derrida, Cátedra, Madrid, 1994, p. 155.

20 Idem., p. 157. 
mecánica cruda [...] el centro de gravedad de la causación parece situarse en el factor de la sorpresa, en el terror, y que un simultáneo daño físico o herida contrarresta en la mayoría de los casos la producción de la neurosis"21.

A propósito de lo anterior, cobra fuerza la cuestión del retorno de lo demónico entendido como retorno eterno de lo mismo, con la repetición del Más allá del principio del placer. ¿Qué es lo demónico mismo que se repite? Lo demónico, nos dirá Derrida, es aquello que retorna sin ser llamado por el principio del placer. Es el retornar que retorna su entrada, volviendo de no se sabe dónde, heredado de no se sabe quién, pero perseguidor por la simple forma de su retorno ${ }^{22}$. Derrida hace la analogía con una especie de cartero sin destino, que rebasa el principio del placer, como estructura del principio del placer en diferido.

En relación con lo demónico de la repetición, retomemos la concepción freudeana respecto de lo ominoso. Freud hace un análisis semántico de la palabra alemana Unheimlich, como la negación (un-) de heimlich, que significa "íntimo", "familiar" y "conocido". Por lo tanto, asume que Unheimlich aparece como una negación, es decir, como lo "no familiar" y "desconocido". Sin embargo, su tesis se centra en que lo conocido puede volverse fácilmente ominoso. "[...] es aquella variedad de lo terrorífico que se remonta a lo consabido de antiguo, a lo familiar desde hace ya largo tiempo. ¿Cómo es posible que lo familiar devenga ominoso, terrorífico, y en qué condiciones ocurre?"23.

En función de esto plantea una relativización de la antítesis heimlich/unheimlich, estableciendo una suerte de conexión entre ambas que deriva en que, lejos de contraponerse, signifiquen lo mismo:

[...] lo más interesante para nosotros es que la palabrita heimlich, entre los múltiples matices de su significado, muestra también uno en que coincide con su opuesta unheimlich. Por consiguiente, lo heimlich deviene unheimlich [...] En general, quedamos advertidos de que esta palabra heimlich no es unívoca, sino que pertenece a dos círculos de representaciones que, sin ser opuestos, son ajenos entre sí: el de lo familiar y agradable, y el de lo clandestino, lo que se mantiene oculto $^{24}$.

En base a lo anterior, Freud retoma la idea de Schelling según la cual lo unheimlich se entendería como todo lo que estando destinado a permanecer en secreto, en lo oculto, ha salido a la luz. Esta idea inmediatamente nos retrotrae, una vez más, a la noción de inconsciente. Prepara así su tesis respecto al mecanismo de lo siniestro, bajo la marca de la

21 Freud, Sigmund, Más allá..., op. cit., p. 12.

22 Derrida, Jacques, La Tarjeta Postal: de Sócrates a Freud y más allá, Siglo XXI, México, 1986.

23 Freud, Sigmund, "Lo Ominoso", en Obras Completas, vol. XVII, Amorrortu, Buenos Aires, 2001, p. 220.

24 Ibidem., pp. 224-225. 
repetición, por el retorno de lo familiar reprimido ${ }^{25}$. Dicha tesis tiene relación con la idea del doble o el alter ego, como posibilidad que tiene el yo de tratar una parte de sí como si fuera otro. Esto, que según el psicoanalista remitiría a tempranas fases de la constitución psíquica, operaría como una modalidad defensiva frente a la destrucción potencial del yo y frente al poder de la muerte. Sin embargo, una vez superada esta etapa, este doble pasaría a constituirse como el ominoso anunciador de la muerte.

Este elemento siniestro u ominoso en Freud se conecta con la compulsión a la repetición citada en el texto Más allá..., entendida como la repetición no deliberada de algo en sí mismo inofensivo que, sin embargo, nos pone en presencia de lo fatal e inevitable. Lo anterior, dado que la actividad psíquica inconsciente se encontraría dominada por el mentado automatismo o impulso a la repetición inherente a la esencia misma de los instintos que se sobrepone al principio del placer. Por lo tanto, se sentirá siniestro en tanto sea capaz de evocar este impulso de repetición interior.

El tercer ángulo del triángulo ominoso/repetición, vendría a estar dado por la muerte. Freud tomará este elemento para su análisis considerando las actitudes ante la muerte y su relación a lo irrepresentable. Así, señalará que no hay nada, desde las épocas primordiales, que se haya mantenido en esencia tan inamovible como la muerte, siendo esta la razón por la que lo ominoso aparece siempre ligado a esto en tanto im-predecible: "Es probable que conserve su antiguo sentido: el muerto ha devenido enemigo del sobreviviente y pretende llevárselo consigo para que lo acompañe en su nueva existencia"26. Así, Freud instala dicha categoría (muerte/irrepresentable) como un elemento más dentro de su propuesta respecto a lo ominoso, pero con una particularidad: la represión quedaría fuera en esta ecuación, "Dada la inmutabilidad de la actitud ante la muerte, cabría preguntar dónde ha quedado la condición de la represión, necesaria para que lo primitivo pueda retornar como algo ominoso. Empero, ella subsiste [...]"27.

Lo ominoso se juega en esta relación en que el lenguaje abandona su causa de sentido y retorna hacia un estadio previo, que pone al sujeto en relación con su propia constitución. "El lenguaje resbala bajo el sentido; el sentido oscila, flotante, sobre el lenguaje: "nosotros nos desleímos". La palabra unheimlich habla, en cierto modo, de la Unheimlichkeit del lenguaje como tal: en ella habla lo desazonador, lo radicalmente no humano del lenguaje mismo" 28 . De este modo, se pone en juego esta suerte de recíproca extrañeza entre el sentido y el lenguaje.

A partir de lo anterior, estamos en condiciones de articular los aspectos fundamentales

Oyarzún, Pablo, “La Cuestión de lo Siniestro en Freud”, Revista de Teoría del Arte, Tomo VIII, Universidad de Chile, 2003.

26 Freud, Sigmund, Lo Ominoso, op. cit., p. 242.

27 Ídem.

28 Oyarzún, Pablo, op. cit., p. 61. 
de la vinculación entre la vida y la muerte que está en el origen tachado del sujeto psicoanalítico, a propósito de la triangulación siniestro-repetición-muerte. Como primer punto señalamos, retomando al propio Freud, que la repetición no es condición suficiente para pensar lo ominoso. Pareciera ser, más bien, que el carácter impulsivo que da Freud a la repetición determina su condición: se sitúa al margen de todas las capacidades y funciones del sujeto en cuanto sujeto -racional-, infundiendo en éste el sentimiento de estar de antemano secuestrado o poseído por una fuerza irresistible que es radicalmente ajena a sus capacidades y funciones. Sería esto, en última instancia, lo que le conferiría el carácter demoníaco a la experiencia en cuestión, siendo el nombre de esa fuerza esencialmente otra y en sí misma innombrable.

Desde esta lógica podríamos pensar, en términos lacanianos, que lo siniestro viene a constituir la emergencia de lo Real en su carácter de irrepresentable. Por otro lado, la repetición siniestra es aquella que se remite y repite a sí misma, con independencia y antelación respecto de todo contenido psíquico que se quiera. En el retorno de lo reprimido, lo que pesa como poder es el retorno mismo, como flujo, y no el contenido que ha sido reprimido; la repetición siniestra goza de autonomía absoluta. Esta mismidad radicalmente otra de la repetición es, según Pablo Oyarzún, lo siniestro:

[...] entonces cabría pensar que el un- de lo Unheimlich tendría el carácter de una negación que no pertenece ni puede ser incorporada a ninguna dialéctica. Principio de otra economía, de un gobierno de la casa que es más antiguo que toda la casa y de la circulación de una cosa que no ingresa como tal en ningún intercambio, sería ella la condición de posibilidad de todo don, como lo que se pone de manifiesto en el juego infantil del fort-da, en ese lenguaje esencialmente no humano -es decir, el lenguaje mismo- que da lo que es como permanente ausencia ${ }^{29}$.

A propósito de lo planteado por Oyarzún, lo anterior se puede ver reflejado en la escritura especulativa que describe el juego del Fort/Da del nieto de Freud, a partir de una historia autobiográfica en que el pequeño Ernst juega con un carrete a tirar y acercarlo hacia él. Surge de este juego una hipótesis interpretativa doble: por un lado, una satisfacción de dominio (frente a la ausencia de su madre) que remitiría a un interés primario. Por otro, el juego será interpretado desde una función negativa: el placer consistiría en hacer desaparecer. A pesar de lo negativo de lo anterior, sería igualmente placentero en la medida que habría un interés secundario derivado en un desplazamiento y transformado en un impulso de venganza hacia la madre.

Lo que Freud denomina "juego completo", como las dos fases del mismo (ausencia/ re-presentación), no puede ser visto en una relación dialéctica de opuestos. En el retorno, 
diría, hay un mayor placer que en la ausencia, por lo que en esta re-aparición habría algo anterior al principio del placer que está siendo reeditado que no es el principio del placer, pero que lo fundamenta. Una repetición originaria, enteramente otra cosa, que para poder ser otra cosa no se debe oponer al principio del placer. Podríamos decir, para no caer en la dialéctica del amo y el esclavo hegeliana que gira en torno al reconocimiento, que constituye una re-petición (volver a solicitar) que en su aparición busca (re)apropiarse de sí misma a partir del re-, es decir, del volver en general, sin deudas ni ataduras. Dicho en términos derridianos, sería el ir-volver, en donde el (-) representa la conexión del retornarse del retornar. El archivo se repite, más para borrar la (propia) huella. La propiedad entre paréntesis marca la diseminación del origen como tachadura.

Por lo tanto, podemos pensar el juego del pequeño Ernst desde está lógica que desborda sus propias reglas y que a su vez se resiste a una articulación interpretativa. El carrete no opera como objeto suplementario de algo otro, sino que el carrete actúa como suplementario del carrete suplementario, consigo mismo como sujeto/objeto en el espejo/ $\sin$ espejo $^{30}$. La importancia de esta aclaración radica en la diferencia entre un principio del placer rector, que si bien no se opone a una repetición, e incluso la incluye, tampoco la determina. Esto elimina el riesgo de pensar la presencia de la ausencia, sino como ir-volver del fort/da: fort:da. La escena del fort/da está siempre describiendo de antemano, en reporte diferido, la escena de su propia descripción. La escritura de un fort/da es siempre un fort/da, en donde se buscará el principio del placer y su pulsión de muerte en el agotamiento de este abismo. Se trata, en definitiva, del alejamiento de lo lejano y del acercamiento de lo cercano ${ }^{31}$.

Lo anterior permite llegar al punto en que Derrida señala que la compulsión a la repetición inserta la pregunta respecto a algo más original y pulsivo que el principio del placer. Ya había quedado establecido el hecho que el principio del placer opera como estructureante del aparato psíquico, en una relación de diferimiento con el mismo, lo que articula un principio de realidad. Al ser la repetición lo originario, no habría nada que la preceda y, por lo tanto, dicho origen se ve expuesto a una deconstrucción general. La repetición colaboraría con el principio del placer, haciéndose pasar por subsidiaria del mismo, dejándose repetir por él, pero en esta misma repetición se abalanza sobre él determinándolo, amenazándolo y persiguiéndolo: "buscando un placer desligado que se parece, como una burbuja a otra burbuja, a un desplacer escogido en su atrocidad misma"32.

Si hay algo que excede al principio del placer, o mejor dicho que lo anticipa, lo excede y lo desborda a partir de su repetición, sería una pulsión que actúa sobre la pulsión misma. En esta línea sería algo así como lo pulsional de la pulsión que Derrida sitúa en el terreno de lo propio, de lo que excede la dualidad -metafísica- entre la vida y la muerte. De tal

30 Derrida, Jacques. La Tarjeta Postal: de Sócrates a Freud y más allá, op. cit.

31 Ídem.

32 Ibídem, p. 332. 
modo que la aporía de reapropiación (así como la de la pulsión y la de la repetición), es que no hay si mismo del que apropiarse. Dicho de otro modo, el retorno pulsional descrito por Freud en su Introducción al narcisismo, más que encontrarse con una identidad clausurada y cerrada sería el encuentro con un lenguaje entendido como repetición del trauma originario, es decir, un lenguaje que no es más que puro diferimiento, como mecánica de un (in)acabamiento en tránsito, de un rodeo entre la propiedad y su propiación. Pura posibilidad eterna e infinita del (re-). En esto, la muerte (más originaria que la dualidad vida/ muerte) viene a reapropiarse de lo que pertenece a si incluso antes que se constituya el si. Es la muerte entendida como pura posibilidad de la imposibilidad.

Lo anterior se puede apreciar en la descripción que el propio Freud realiza respecto de las pulsiones conservadoras, entendidas como centinelas de la vida. Sin embargo, dirá, estas mismas son originalmente guardias o satélites de la muerte que no pueden sino permanecer fieles a su primer destino. Dichas pulsiones, parciales, serían las que en un momento habrían intentado guardar a la vida, pero que en ellas ya habían guardado a la muerte para salvar la propia muerte, en una suerte de mecánica autoinmunitaria. Queda de manifiesto, entonces, el hecho de que la muerte se constituye como necesidad interna de la vida, camino (ya) (a)propiado (de) hacia la muerte.

Al centrar el foco sobre la muerte, aparece inevitablemente el tema de los límites. En otros términos, surge la pregunta respecto a los modos en que esta muerte puede ser comprendida en su relación con(tra) la vida misma. Es una muerte que en su afirmación niega, que en su posibilidad se encuentra la imposibilidad del ser. Es por esto que Derrida, a propósito de su lectura de Heidegger, nos dirá que se hace necesario alejar la muerte de su comprensión como simple aniquilación. De modo que la muerte no puede más que ser aporía, es decir, differancé del ser consigo del presente, a partir de un doble concepto de frontera: otro que ya no es su otro.

En esta línea, la palabra muerte aparece como irrepresentable, como objeto de experiencia irrecusablemente determinante. Por lo tanto, si la muerte ha de ser considerada como aquello imposible, será aquello que no puede pasar ni suceder, ni siquiera como representación del no paso - privación del paso-. La muerte será la frontera entre lo posible y lo imposible, estará absolutamente desterritorializada pero, en su ausencia, permitirá nombrar la presencia/ausencia. La cuestión de lo que es la muerte está radicalmente ausente $^{33}$.

Volviendo sobre el análisis ontológico de la muerte, se podría pensar que si la muerte es, es cada vez esencialmente la mía. Esto hace que el problema deje de centrarse en la muerte-ausencia para desplazarse hacia la muerte como identidad de propiación. Además supone dejar de pensar la muerte como frontera, a saber, meramente como fin que sobre- 
viene con la madurez. Por el contrario, lo que hace la analítica existencial de la muerte heideggeriana es hacernos explícita la cuestión de la muerte como subordinada a una característica de la constitución fundamental del Dasein -la muerte como inmanente-, asunto que la hace absolutamente prioritaria.

La preocupación por pensar la muerte propia del Dasein es el propiamente morir que pertenece a la potencialidad de lo propio y auténtico del Dasein, a saber, aquello de lo que hay que dar testimonio y presentar a la atestiguación. En esto, Heidegger propone una delimitación ontológica respecto de los campos de cuestionamiento de la muerte en que separa el finalizar del propiamente morir. Es aquí donde aparece la aporía derridiana: en la experiencia de la imposibilidad entendida como la apropiación de una imposibilidad que desborda los límites difuminándolos y cuestionando todo lo que hasta antes se definía como tal. Arribante absoluto que sorprende al anfitrión, indeterminando su condición, que aún no es un anfitrión, hasta aniquilar o indeterminar todos los signos de una identidad previa, empezando por la frontera que delimitaba el en casa legítimo y que garantizaba las filiaciones, nombres, familias y genealogías -el un-del-heimlich $-^{34}$. Lo anterior paraliza la posibilidad mimética del lenguaje como función del nombrar, identificar e interpretar y, de paso, la capacidad de identificación que posee el sujeto de la conciencia. Sería, más bien, el lugar de la repetición sin nombre en la especulación freudiana: una disrupción sin representación ni deuda que negar ni reprimir. Arribante que borra, empuja al olvido a aquello otro y en el que lo otro se olvida de su oposición. Es la figura que, a los ojos de Freud, ocuparía el espacio de la familiaridad siniestra (unheimlich).

Tal y como señalamos, la distinción entre el perecer y el propiamente morir se retrotrae a una relación con el habla. Heidegger dirá que el mortal será aquel que pase por la experiencia de la muerte "como tal". Habrá que preocuparse, entonces, por lo que hace la comprensión de lo que es la muerte para el Dasein. Consiste en preocuparse por lo que hace posible ya cualquier enunciado, cualquier tema o cualquier proyecto. Petición autoconcedida de un fundamento de una analítica existencial de la muerte que funde todos los otros discursos sobre la muerte. El caso de la muerte, desde esta posición de fundamento, es uno especial ya que remite a un orden completamente distinto. Hay cuestiones legítimas del fundamento y del ya de la condición de posibilidad que resultan posibles y necesarias en virtud de una relación con la muerte, de un la-vida-la-muerte que no forma parte del caso de lo que este hace posible. Sería una analítica anterior, libre, primera y neutra; analítica anterior incluso a la de las respuestas que dependen de una metafísica de la muerte. En este sentido, Heidegger plantea que el psicoanálisis puede, en el mejor de los casos, ser una psicología del moribundo pero en ningún caso un discurso sobre el morir. Esto, en todo caso, atentaría en contra de la analítica existencial de la muerte, en tanto el Dasein sería incapaz de dar testimonio de la muerte ${ }^{35}$. 
Si el ser-posible (como potencialidad) es el ser propio del Dasein, entonces la analítica existencial de la muerte del Dasein tiene que hacer de esta posibilidad su tema. Pero por otro lado, la muerte es la posibilidad por excelencia: la muerte se constituye en la posibilidad más propia del Dasein. Con la muerte, el Dasein se espera él mismo en su poder-ser más propio. "El esperarse implica una inminencia de una triple transitividad: algo que llegará como lo otro/radicalmente otro de uno mismo, precediéndose uno mismo como si tuviera una cita uno consigo mismo que uno es y no se conoce" $"$.

La muerte es el único caso de esta posibilidad de la imposibilidad. Porque de lo que se trata es de la imposibilidad de la existencia misma. Cualquier otra posibilidad o imposibilidad tendría sentido y se definiría en sus límites a partir de la posibilidad de la imposibilidad, de esta imposibilidad.*

\section{Bibliografía}

Bennington, M., Jaques Derrida, Cátedra, Madrid, 1994.

Derrida, J., Aporías. Morir - esperarse (en) los límites de la verdad, Paidós, Barcelona, 1998.

, Mal de Archivo. Una impresión freudiana, Trotta, Madrid, 1997.

, "Freud y la Escena de la Escritura", en La Escritura y la Diferencia, Anthropos, Barcelona, 1989.

, “La Différance”, en Márgenes de la Filosofía, Cátedra, Madrid, 1988.

, La Tarjeta Postal: De Sócrates a Freud y más allá.., Siglo XXI, México, 1986.

Freud, S., "El yo y el ello (1923)", en Obras Completas, XIX. El yo y el ello y otras obras, Amorrortu, Buenos Aires, 2001.

, "Más allá del principio del placer (1920)", en Obras Completas, XVIII. Más allá del principio del placer. Psicología de las masas y análisis del yo y otras obras, Amorrortu, Buenos Aires, 2001.

35 Ídem.

36 Ibidem., p. 109.

* Artículo recibido: 5 de junio de 2014. Aceptado: 15 de julio de 2014. 
-----------, “Lo ominoso (1919)", en Obras Completas, XVII. De la historia de una neurosis infantil y otras obras, Amorrortu, Buenos Aires, 2001.

"Introducción al Narcisismo (1914)", en Obras Completas, XIV. Contribución a la historia del movimiento psicoanalítico. Trabajos sobre metapsicología y otras obras, Amorrortu, Buenos Aires, 2001.

Goldschmidt, M., Jaques Derrida, una introducción, Nueva Visión, Buenos Aires, 2004.

Mayor, R., Lacan con Derrida (Análisis Desistencial), Letra Viva, Buenos Aires, 1999.

Oyarzún, P., "La Cuestión de lo siniestro en Freud", Revista de Teoría del Arte, Tomo VIII, Universidad de Chile, 2003. 